\title{
Adoption of, the Palestine Green Building Design Approach, with the Help of Checklist Tools
}

\author{
Usama I. Badawy1, Abdelkhalek I. Alastal'2, Muain Q. Jawabrah ${ }^{3}$, Raed A. Salha ${ }^{4}$ \\ ${ }^{1}$ Engineering and Camp Improvement Department, United Nation, Palestine \\ ${ }^{2}$ Geography and GIS Department, Arts College, Islamic University of Gaza, Gaza, Palestine \\ ${ }^{3}$ Architecture and Planning Department, Birzeit University, Birzeit, West Bank Palestine \\ ${ }^{4}$ Geography and GIS Department, Arts College, Islamic University of Gaza, Gaza, Palestine \\ Email: ubadawy@yahoo.com, abdelkhalek.alastal@gmail.com,mqasem@birzeit.edu, msalha@iugaza.edu.ps
}

How to cite this paper: Badawy, U.I. Alastal, A.I., Jawabrah, M.Q. and Salha, R.A. (2021) Adoption of, the Palestine Green Building Design Approach, with the Help of Checklist Tools. Journal of Environmental Protection, 12, 49-74.

https://doi.org/10.4236/jep.2021.121005

Received: December 16, 2020

Accepted: January 24, 2021

Published: January 27, 2021

Copyright $\odot 2021$ by author(s) and Scientific Research Publishing Inc. This work is licensed under the Creative Commons Attribution International License (CC BY 4.0).

http://creativecommons.org/licenses/by/4.0/

\begin{abstract}
Nowadays our world is faced with various environmental problems. These environmental problems are caused by the increasing pollution in the world, increasing production and consumption of material goods. These problems have serious consequences for human health and also have a major impact on natural ecosystems. This paper discussed sustainable green building in terms of key principles for sustainable building, strategies and guidelines for sustainable green building, and steps for an integrated approach to green design. The study also looked at the status of green building and sustainability, as well as green building materials in Palestine. The study suggested a checklist to help assess the condition of buildings in Palestine and the extent to which they respond to the principles of sustainable green buildings, thus, contributing to help new and existing buildings to adopt a sustainable green building approach, in order to achieve the goals of sustainable green construction in terms of saving energy and resources and reducing waste, therefore, participating in preserving the environment and improving the quality of life.
\end{abstract}

\section{Keywords}

Global Warming, Building Materials, Green Building Sustainability, Checklist for Green Building

\section{Introduction}

Architectural sustainability means meeting the needs of today's generation without weakening the opportunity of future generations by maintaining eco-logical bal- 
ance to fulfill the necessities. A sustainable society can meet its needs by using natural resources without harming the environment [1].

The construction sector is rated first as a single contributor to carbon dioxide emissions and, referring to a report by the United Nations Environment Program, about two-thirds of global energy consumption occurs in buildings. (UNEP) [2]. Green buildings have the greatest potential to be a solution for mitigating environmental effects and reducing environmental emissions. Taking into consideration the economic aspect of sustainability is one of the fundamentals of green design process. Low use of water and other natural resources, improved public health, increased efficiency and improved quality of indoor air are most of the other side effects of green building [3] [4].

Many researchers define the modern green building, that it is a basic design based on raising the efficiency of the use of resources, considering the minimum impact on human health and the surrounding environment during the building life cycle. We also can clearly notice that green buildings have many tangible, measurable and intangible effects on the environment and man. Reduction of energy and water consumption has a tangible effect that appears on the first day of constructing the green building. The quality of the ventilation, the comfort of the heat, the healthy atmosphere, the well-being, and the light are all benefits that the inhabitant feels from the first day [5].

Green building is an advanced concept for the construction industry to improve building productivity, consume energy and rationalize the consumption of construction and the significance of the building to the surrounding environment with the least damage, all of which is reflected in human health and well-being [6].

As a result of the development of green buildings, there was a need for general systems and measures to evaluate the green building, but there is no unified global system to evaluate the performance of the green building. Based on this need, many countries around the world have developed their own systems and tools, this is known as building environmental assessment methods (BEAM) [7] [8]. Britain depends the British Research Establishment Environmental Assessment Method (BREEAM), while United States adopts the American Leadership in Energy and Environmental Buildings (LEED), it is a globally recognized system widely deployed in several countries.

This research discusses the environmental impacts of green and sustainable architecture and aims to define key factors affecting the design of green buildings and sustainable urban development. To obtain a decent green design for buildings, the research identified various components and procedures required. This research hypothesizes that consider the various environmental considerations for sustainable and green architecture should improve energy efficiency of buildings and generally improve the quality of the built environment in developing countries, in addition to identifying the main factors that influence urban development in Palestine., Taking into account the Palestine Higher Green Building Council criteria, such as Palestine, in particular the Gaza Strip, 
by developing a checklist to evaluate the different elements of green buildings in Palestine, (PHGBC).

\section{Related Works}

In the fact, Palestine as a developing country and prohibited from exploiting its natural resources such as water and natural gas, and even producing or importing electricity. The design of green energy-saving buildings, combined with the exploitation of renewable energy resources, especially solar energy, is the only way out of the current situation.

Source [9], Addressed the barriers and obstacles facing Palestinian green building architecture. The author split the problems into two major categories: technical and organizational difficulties. Compared with Palestine, as presented in regional experiences. He also called for sustainable building materials to be used as a future for green building in Palestine, and called for renewable energy to be used as a future sustainability agenda in Palestine.

Source [10], Investigating the current water and energy consumption data being used by Green School and matching it with the actual water and energy consumption reports for 205 West Bank public schools in 2016.

Source [11], The author stated that the traditional Palestinian architectural model is an example of buildings adapted to the Palestinian landscape and culture, and raised the possibility of adopting the idea of courtyards in Palestinian homes as a proposed sustainability strategy. Therefore, the concept of the courtyard is a component that can be reintegrated into future Palestinian sustainable housing and green buildings.

Source [12], reflecting on one aspect of the building, the exterior walls, as the building envelope responsible for conserving energy and making the building more efficient and sustainable, the writer said that Palestine's building systems do not adopt the sustainability strategy, which increases the cost of running the building.

Source [13], Dealing with the development of green residential buildings in Palestinian cities, highlighting the need to improve residential buildings in $\mathrm{Pa}$ lestine in line with climate and environmental patterns, to enable use of alternative renewable energy technologies and to reduce heat within buildings, taking conventional Palestinian techniques into account, The author concluded that for a range of reasons, the old buildings provided a better climatic atmosphere than modern buildings, the most notable of which are: heat insulation, steering, shading, and ventilation.

Source [14] They went to study two samples in two separate climate zones, Nablus and Jericho, working with school buildings as they tried to determine thermal comfort and energy efficiency. The researchers concluded that the reality of schools in Palestine is far from the energy efficiency comfort required. Energy needs improvements to maintain the lowest level of energy consumption.

Source [15], It concluded that serious efforts have been made by the Ministry of Education to improve school building and its comply with high performance 
green design guidelines by adopting such aspects and meeting with mandatory criteria, in general those which can also be applied within the framework of simple financial possibilities.

\subsection{Challenges Facing Green Buildings Approach}

\subsubsection{Global Warming}

The phenomenon of global warming, or greenhouse phenomenon, is characterized as a rise in the average atmospheric pressure in the lower layer of the surface of the earth over the last century or two centuries when, after entering it, the sun's heat is absorbed or lost in the earth's atmosphere, which raises the temperature of the earth and makes it warmer. This is done by absorbing and confining greenhouse gases such as carbon dioxide from the energy of the sun close to the surface, which leads to global warming. A global mean temperature rise does not necessarily mean that all regions of the planet will get warmer, since global warming does not imply a global mean temperature rise of the same amount, but it does indicate a global mean temperature rise in general, Despite the existence of studies showing that the effect of global warming goes far beyond rising temperatures, as it has a significant impact on the occurrence of climate change around the world and on global weather patterns, it should be noted that global warming offers just a summary of the increase in global average temperature. Influencing climatological components such as rainfall rates. It is generally possible to name four different parameters to allow the global climate to continue to rise (see Table $1 \&$ Figure 1):

- Changes in solar radiation incidents.

- Changes in renewable energy reflected radiation.

- Thermal radiation shifts released into space.

- Internal fluctuations of the climate system.

\section{1) How is global warming linked to extreme weather?}

Greenhouse gases: Greenhouse gases or greenhouse gases, such as carbon dioxide, are classified as naturally occurring atmospheric ring gases. It adapts to the ability of living organisms to survive on their surface, and its substantial increase due to human factors creates an imbalance in climatic change and global warming, which causes global warming, despite its important role in sustaining the Earth's temperature.

Causes of global warming Human causes Human behaviors directly contribute to climate change through the human use of fossil fuels through their different modes of activity, as the combustion of fossil fuels contributes to the atmospheric production of greenhouse gases such as carbohydrate dioxide, which leads to a change in the environment as the quantity of aerosols and clouds "airborne particles."

A significant cause of carbon dioxide emissions is increasing the concentration of carbon dioxide in the atmosphere through the burning of fossil fuels and the use of agricultural land in a different way than before, such as the clearing of forests for architectural expansion. 


\section{Global warming}

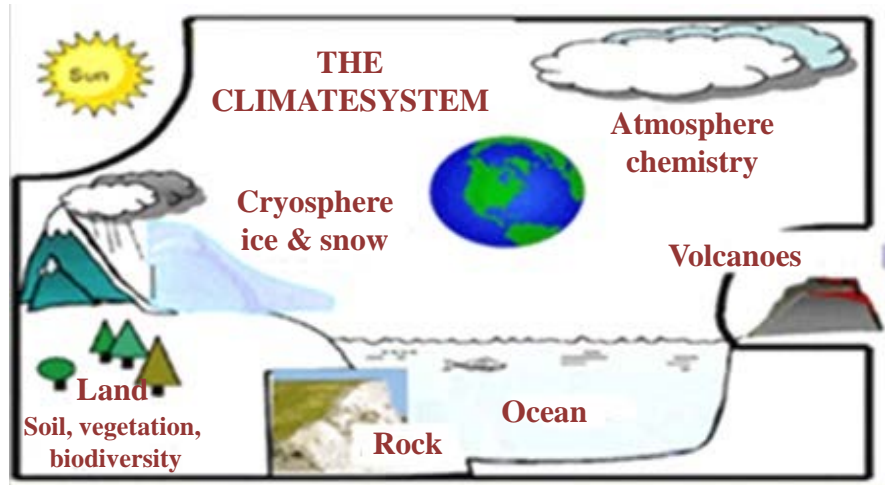

Figure 1. Global warming, US, Environmental protection Agency, 2020.

Table 1. Main challenges facing green buildings approach.

\begin{tabular}{ll}
\hline Category & Description \\
\hline \multirow{2}{*}{ Polices } & - Lack of enforcement of sustainable building policies. \\
& - Lack incentives form the government. \\
& - Lack of urban planning and land use policy. \\
\hline & - Additional costs caused by green construction. \\
Cost & - Incremental time caused by green construction. \\
& - Lack of financial instruments for green building. \\
\hline & - Uncertainty in the performance of green materials and equipment's. \\
Awareness & - Misunderstandings of green technological operations. \\
& - Conflicts in benefits with competitors. \\
& - Lack empowerment of stake holders.
\end{tabular}

- The climate influence of global warming Global warming has a direct impact on the climate and has the following impacts.

- Changes in rainfall amounts: increasing global average temperatures contribute to higher evaporation rates, accelerating the occurrence of the water cycle, as steam rising into the atmosphere will lead to higher precipitation levels, noting that it will not be distributed evenly in all regions of the world except in some regions. In summer, winter will be wetter and drier, and global average rainfall will rise from 3 percent to 5 percent, according to studies.

- Snow and ice melting: A warm atmosphere contributes to the melting of ice on the surface of the earth, such as rivers or ice caps, and in the summer, snow. Furthermore, forecasters predict that in the northern seas there will be a lot of sea ice floating and in the 21st century the south will decrease without determining the exact amount of melting.

- Increasing the acidity of the oceans: by removing some of the accumulated heat and carbon dioxide from the atmosphere, the oceans on the earth's surface help minimize the climate changes that occur in the planet. However, water and carbon dioxide have had several impacts that increase or intensify ocean acidification. After these reactions, the acidity of the oceans has re- 
sulted in a reduction in acidity, such that a rise in acidity from 0.14 to 0.35 $\mathrm{pH}$ is expected by the year 2100 , which may cause more problems for marine species.

- Effect on ocean currents: ocean currents occur because of the variation in ocean salinity and temperature as the temperature of the ocean increases along with its increases in salinity due to different factors, including: Related to the melting of ice into the seas, changed precipitation rates and a rise in freshwater flow contribute to a disturbance of the flow movement or a disruption of the oceans' thermal salt cycle, which has a strong climate effect.

- Weather change: Some climatologists suggest that hurricanes, including tropical cyclones, would (and may well have begun) change as a result of global warming, as the surface waters of the oceans provide the energy required to cause storms. It is predicted that hot-water oceans will increase the strength of hurricanes and the power of their destruction over time.

- Changing the carbon cycle: Global models of the carbon cycle imply that the Earth system absorbs less carbon dioxide from the atmosphere as the atmosphere warms up, exacerbating the issue of global warming.

- Changes in the biological system of life: temperature rises impact different biological processes, e.g., B. The change in the geographical areas of wild plants and animals, the attributes of wild and domesticated "domesticated" animals, the length of the cycles of vegetation and the variations in the dates of freezing.

\section{2) Solutions to the global warming problem}

We concentrated on the suggested strategies that can be introduced to limit global warming, including:

- Energy efficiency improvement: The most important role in global warming is played by the energy systems used to heat and cool buildings. Energy efficiency thus allows fewer quantities to be used and the same production and services to be provided, which helps to save energy and money.

- Improvement of the transport sector: substantial emissions of gases are generated by the transport sector and these emissions have risen rapidly over the past decade, with the result that these emissions should be reduced.

- Phase out power from fossil fuels progressively.

- Development of new low carbon fuel economy technologies.

- Ensuring Sustainable Development: Each region of the globe has various consequences for the issue of global warming and its capacity to cope with the problem. Generally speaking, all countries should work together to resolve the problem, to help developing countries adjust to the effects of climate change and to enhance their ability to turn to low-carbon fuels.

- Modernizing Renewable Energy Sources: Various studies have shown that renewable energy sources such as solar, bio and other renewable energy sources, in addition to their emissions mitigation benefits and reasonable costs, can meet much of the world's energy needs. It is necessary, therefore, to depend on it more. 
- Reduction of carbon dioxide: This is done while preserving the operation of the critical structures. How forests and oceans do their natural job as carbon sinks by ending deforestation and constantly encouraging agriculture to prevent habitat loss in the oceans.

\subsubsection{Geographical Location and Climate Zones in Palestine}

\section{Geographical location of Palestine}

Geographically, Palestine is located in-between $34.15^{\circ}$ and $35.40^{\circ}$ east longitude and $29.30^{\circ}$ and $33.15^{\circ}$ north latitude. The Palestine map further indicates the climatic condition and heterogeneous topography of the country. Spread over total area of 27,000 sq km, Palestine is encircled by Jordan and Syria in the east and Lebanon in the north. Situated on the shores of the Mediterranean Sea, see Figure 2 \& Table 2.

Palestine today consists of the West Bank and Gaza Strip, forming 23\% of the total area of historic Palestine while it was under the British Mandate, before the Israeli occupation in 1948. Gaza Strip is located on the western side of Palestine adjacent to the Mediterranean Sea [16] [17]. West Bank is situated on the central. The extension of West Bank is from the Jordan River in the east to the cease-fire line in the north, west, and south [18]. According to the Palestinian Central Bureau of Statistics, the total area of Palestine is 6020 square kilometers, whereas, the area of West bank is approximately 5655 square kilometers, Gaza Strip is 365 square kilometers [19].

Table 2. Climate zones in Palestine.

\begin{tabular}{ll}
\hline Climate Zones & Description \\
\hline First zone & $\begin{array}{l}\text { Occupies an area of } 1103.3 \mathrm{~km}^{2} \text {, Hot and dry in summer, warm winter: This } \\
\text { climatic zone extends along the eastern slopes, including the Dead Sea and part of } \\
\text { the Jordan Valley, Characterized by a hot and dry climate in summer and warm } \\
\text { winter. Its cooling loads increase significantly in summer. }\end{array}$ \\
\hline Second zone & $\begin{array}{l}\text { This area is characterized by a hot, dry climate in the summer and mild winter, } \\
\text { with area } 823.2 \mathrm{~km}^{2} \text { which extends along the eastern slopes of the West Bank. }\end{array}$ \\
\hline Third zone & $\begin{array}{l}\text { It has a Mediterranean Sea climate, a hot summer for half a year, and a mild } \\
\text { winter, Stretching over } 969.1 \mathrm{~km}^{2} \text {, of the entire of the West Bank, a semi-arid } \\
\text { region. }\end{array}$ \\
\hline Fourth zone & $\begin{array}{l}\text { It features a worm, partly humid summer, cold winters, Mediterranean Sea } \\
\text { climate approximately } 47 \% \text { of the total population of the West Bank lives on } \\
\text { 1314.6 km }{ }^{2}, \text { Including Nablus, Jerusalem, Bethlehem, Ramallah, and Al-Bireh, } \\
\text { it is considered to be the heart of the West Bank. It is inhabited by most of the } \\
\text { building. The building materials are natural stone, concrete blocks. }\end{array}$ \\
\hline Fifth zone & $\begin{array}{l}\text { Warm sub-humid summer, temperate winter - Mediterranean Sea climate, the } \\
\text { area covers an area of } 1461.2 \mathrm{~km}^{2} \text {, including Jenen, Tulkarm, Qalqiliya and Salfit. }\end{array}$ \\
\hline Sixth zone & $\begin{array}{l}\text { This area covers the entire coastline and most of the northern and central areas of } \\
\text { the Gaza Strip, where more the } 97 \% \text { of the Gaza Strip's population lives. Its } \\
\text { climate is humid, the average temperature is } 18^{\circ} \mathrm{C} .\end{array}$ \\
\hline $\begin{array}{l}\text { An arid desert climate, inhabited by about } 2.8 \% \text { of the total population of the } \\
\text { Gaza Strip. }\end{array}$ \\
\hline
\end{tabular}




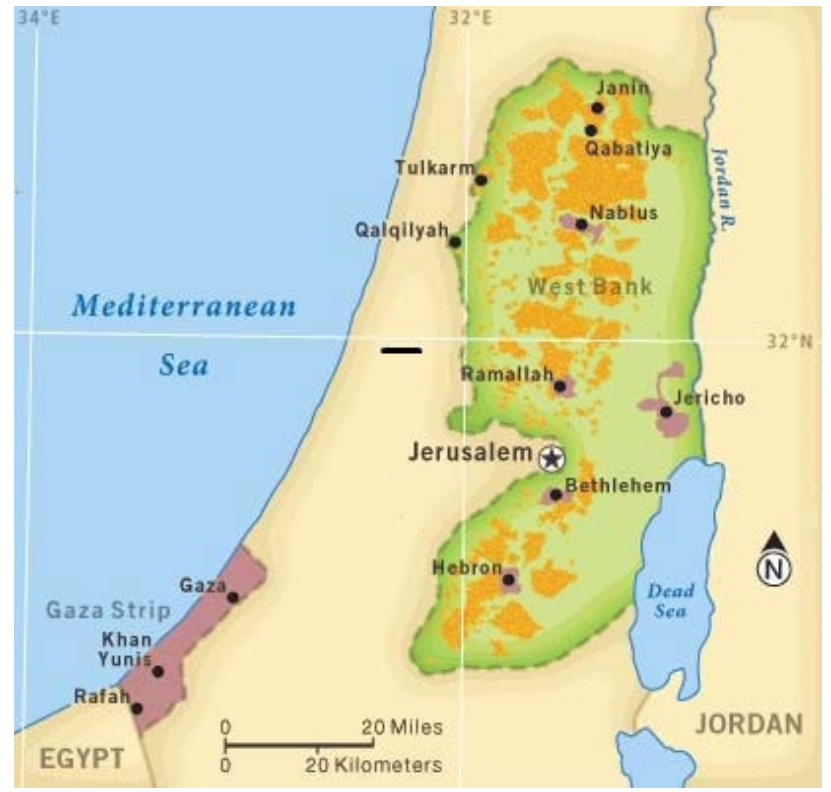

Figure 2. Regions for Palestine [21].

\section{- Climatic Zones in Palestine}

Green building design is primarily based on energy efficiency and reduced cooling and heating loads. Climate analysis, which has a significant impact on energy consumption in buildings, is the cornerstone for adopting green buildings that achieve thermal comfort and energy efficiency. Classification came out in five climatic zones in the West Bank and two in the Gaza Strip [20].

It is clear that Palestine has many climatic zones, which means different temperatures, demographics, and different environmental conditions. This is a challenge to the design of the green building. Each climate zone has its own model [9]. Unfortunately, we would say that the majority of Palestinian designers and the public do not give enough attention to climatic zones and their impact on the design of a sustainable building. Many environmental concerns such as $\mathrm{CO} 2$ emissions, water scarcity, population growth, waste, and pollution are straining our planet's ability to keep pace with our demand for resources. As recently identified, there are alarming environmental problems associated with the construction and operation of buildings, such as: B. Global warming, waste accumulation and the depletion of the ozone layer.

\subsection{Key Principles for Sustainable Building}

It was after the world felt this economic and environmental shock that the principle or style of sustainable design appeared in the 1970s, and it was taken into account that the natural resources of the world are limited and people try mercilessly to use them to take advantage of destruction. Natural raw materials, reducing their use and raising awareness of the environment at the level of governments, states and individuals. At the level of governments, states and individuals, raising awareness of the environment. Then there are the three key reasons for overlapping sustainable architecture and thereby contributing to the 
life, sustainability and continued existence of communities. Sustainable building also has the advantage and value of saving energy on a daily basis, as this is one of the ways in which consumption as decreases the amount of electronic components seen in the building. See Figure 3 [22].

The design process is the process of forming and assembling elements and placing them in a particular configuration to give it a particular purpose or sense, and relies on experience Personality and human behavior from this point on, in all aspects of life and wherever design is related, the systemic sustainable development process begins as design and sustainability have become a successful feature of design.

Sustainable design is the most important pillar of holistic sustainable development and implies the creation of safe management of the environment based on the efficient use of resources and respect for values that foster harmony with the environment, since sustainable buildings strive to reduce their negative impact through efficiency on the environment. Usage of energy and resources; It is therefore important to increase the level of competence and the understanding of architects of the value of this definition and how to design buildings. A general framework for understanding sustainable design should be in place and this is done by the concepts of sustainable design. (1) Sustainable design in three points:

a. Achieve the sustainability of the building tools used.

b. A sustainable building's life cycle.

c. Built to meet humanitarian criteria.

The intersection of architecture, electro-mechanical engineering and structural engineering is sustainable design. In comparison to basic scale, proportion, proportion, texture, shadow and light aesthetics, the building design team has to deal with long-term environmental, economic and human costs. The most commonly used feature of sustainable design can be described, such as:

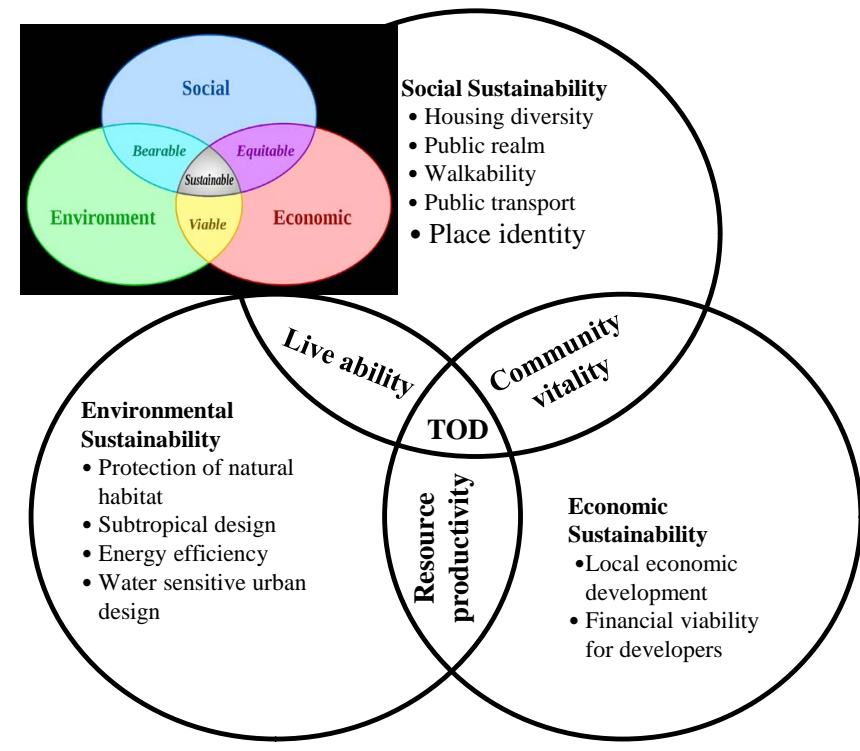

Figure 3. Key principles for sustainable building. TOD means (transit-oriented development). 
A. Comprehensive preparation, architecture and the relevance of simple choices as they have the greatest effect on energy efficiency, e.g.

B. Passive solar architecture that utilizes solar energy, as well as natural light and natural cooling with proper guidance.

C. The expense of sustainable buildings does not have to be more costly than traditional buildings, nor does the simplicity or lack of design complexity vary.

D. System integration as each of the elements is a part of the whole and is required to be successful in that design.

E. The most important concepts for sustainable design are reducing energy use and the preservation and enhancement of people's health.

The concept sustainable construction represents and has been framed by environmentally conscious design approaches in the field of architecture. Sustainable architecture, by and wide, by increasing efficiency and moderation, aims to reduce environmental effect of buildings usage of resources, electricity, space and creation In simpler words, these are ensured by the concept of sustainability or ecological design. Today's actions and our choices should not preclude opportunities for future generations. Thus, green building architectural design environmental solutions and treatments had simultaneously led to economic and health benefits and many social benefits at the individual and community level.

\section{Sustainable Design Principles}

> Understand the site: a design that will help identify the site and the practices for building on the site, such as solar energy and orientation. Natural environment protection and public transport connectivity.

Connection with nature: Development is obtained by connection with nature and the built world. Effective architecture enables us to clarify our status in nature.

Understand natural processes: natural systems consist of closed cycles, there is also no waste in nature.

> Understanding the impact on the environment: Sustainable use and recycling will reduce the negative impact on the environment.

Understand people: must take into account the diversity of cultures and customs of the people who are used and it lives in the built environment.

\subsection{Green Building Sustainable Design Strategies and Direction}

Good design for environmentally friendly building and sustainable architecture is achieved by integrating the essential elements of traditional architecture with new technologies and systems. A sustainable building environment can be achieved by saving renewable energy sources, reducing water, energy and building material consumption, increasing the strength of buildings, comfort for residents, energy saving and operating costs, reducing pollution and waste through reuse and recycling. An environmentally friendly green building is a building that has been designed according to the concept of green sustainability, is comfortable and environmentally friendly, and also saves resources for future gener- 
ations [23].

Green strategies include both active and passive strategies for green sustainable design. Where there are many more passive strategies, early implementation in the design process is required and they tend to be more form-shaping. The overall focus is on the strategies that should be implemented through schematic design. There are six basic principles that persist depending on the source [23], they are:

Site possibility optimization

There are several factors that determine location optimization, including convenient location selection, taking into account the reuse of existing buildings, the location, orientation, and landscaping of a building that affect local ecosystems, transportation systems, and energy use. The site design should be integrated with sustainable green design for a successful project.

- Energy utilize optimization

Due to the problems that the environment and humans face, it is very important to employ strategies to reduce energy consumption, increase efficiency and maximize the use of renewable energy sources. Clarifying the energy efficiency of today's buildings is important in order to increase energy efficiency and conservation (Figure 4).

$\checkmark$ Water conservation and management

Potable water (drinking water) is viewed as an increasingly scarce resource in many parts of the world. Therefore, the sustainable design of green buildings should include efficient water use and management that includes reuse or recycling on site.

Optimization of construction space and material utilization

A sustainable green building must be designed and operated in such a way that materials are used and reused in the most efficient and sustainable way throughout its life cycle. It must be customizable for reuse throughout its life. It is imperative to incorporate materials that add value, reduce pollution and conserve natural resources, see Figure 5.

- Improving the quality of the indoor environment

Indoor climate quality (IEQ) has a significant impact on the health, comfort, well-being and productivity of the building's residents. Sustainable design of green buildings should improve natural lighting, use adequate ventilation and control of humidity, improve acoustic performance, and avoid the use of materials containing highly volatile organic compounds that can cause emissions of volatile organic compounds that can be harmful to health and the environment. Principles of indoor climate quality According to the IEQ, residents must also control building systems such as lighting and temperature.

- Green building operation and maintenance improvement

Construction and maintenance issues should be addressed in the early design phase of a facility to improve the working environment, increase productivity, reduce energy and resource consumption and costs, and also to avoid system failures. The involvement of building operators and maintenance personnel in 
the design and development phase guarantees efficient operation and maintenance of the building. The involvement of building operators and maintenance personnel in the design and development phase guarantees efficient operation and maintenance of the building, see Table 3.

\section{Steps Integrated Green Design Approach}

A green building is a high performing building concept that aims to create an energy efficient, healthy and productive building with minimal impact on the local environment.

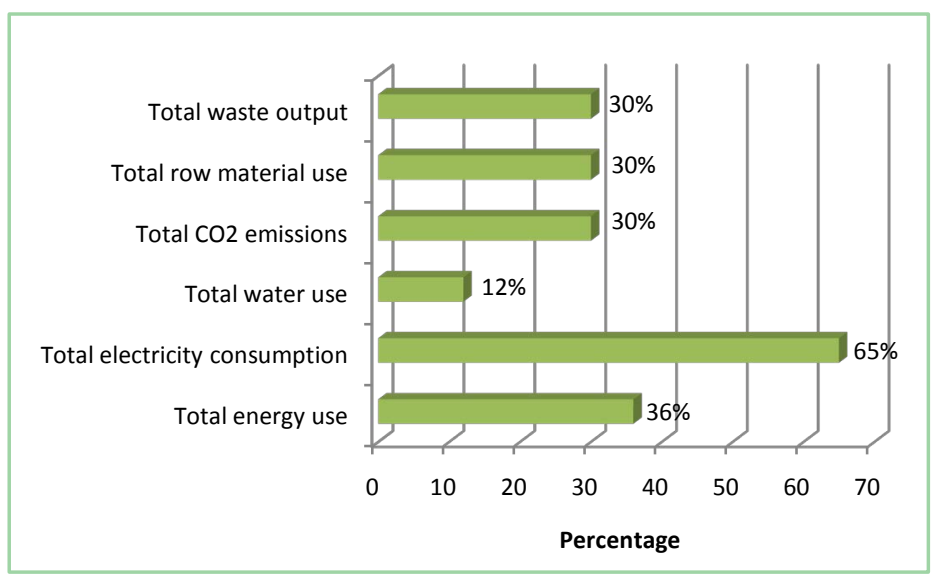

Figure 4. Example of the impact of the building industry on the environment in the USA [23].

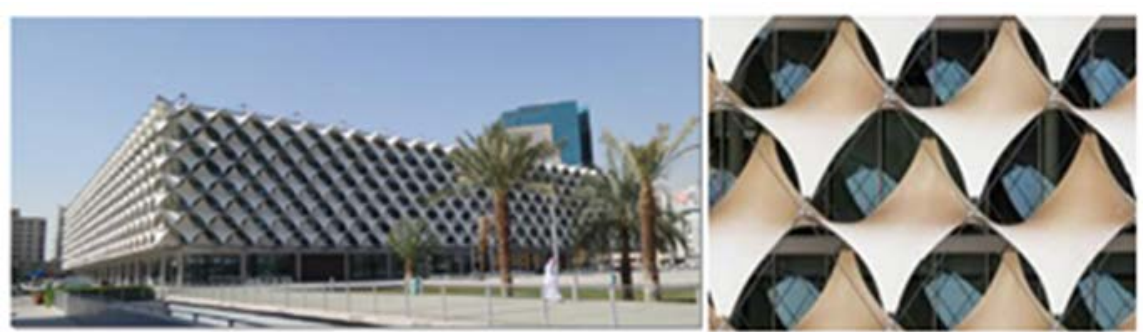

Figure 5. King-Fahad National Library in Riyadh, redesigned and refurbished to include green design strategies [24].

Table 3. Comparison between "Green Buildings" and "Non-Green buildings" or "Traditional Buildings.

\begin{tabular}{ccc}
\hline Type & Green Building & Traditional Building \\
\hline Energy Consumption & Low & High \\
Indoor Environment Quality & Very Good & Good \\
Emissions & Low & High \\
Waste Management & High Efficient & Less Efficient \\
Building Materials & Environmentally Friendly & Not Environmentally Friendly \\
Project Practices & Sophisticated & Normal \\
\hline
\end{tabular}


There is a global direction in the construction industry around the world, led by many national governments and international organizations, to improve environmental conditions, sustainability and urban quality of life. Green buildings are designed to reduce the overall impact on human health and the natural environment in the following ways:

- Using energy, water and other resources efficiently.

- By reducing waste, pollution, and environmental degradation.

A green building is a high performing building concept that aims to create an energy efficient, healthy and productive building with minimal impact on the local environment.

There is a global direction in the construction industry around the world, led by many national governments and international organizations, to improve environmental conditions, sustainability and urban quality of life.

There are three basic principles of sustainable green building design, see Figure 6.

\section{Status of Green Building and Sustainability in Palestine}

The political, geographic, economic and social factors have a major impact on the adoption of the green building and sustainability strategy. The following are the most important of these influencing factors, see Table 4.

Table 4. Status of green building and sustainability in Palestine [9] [23].

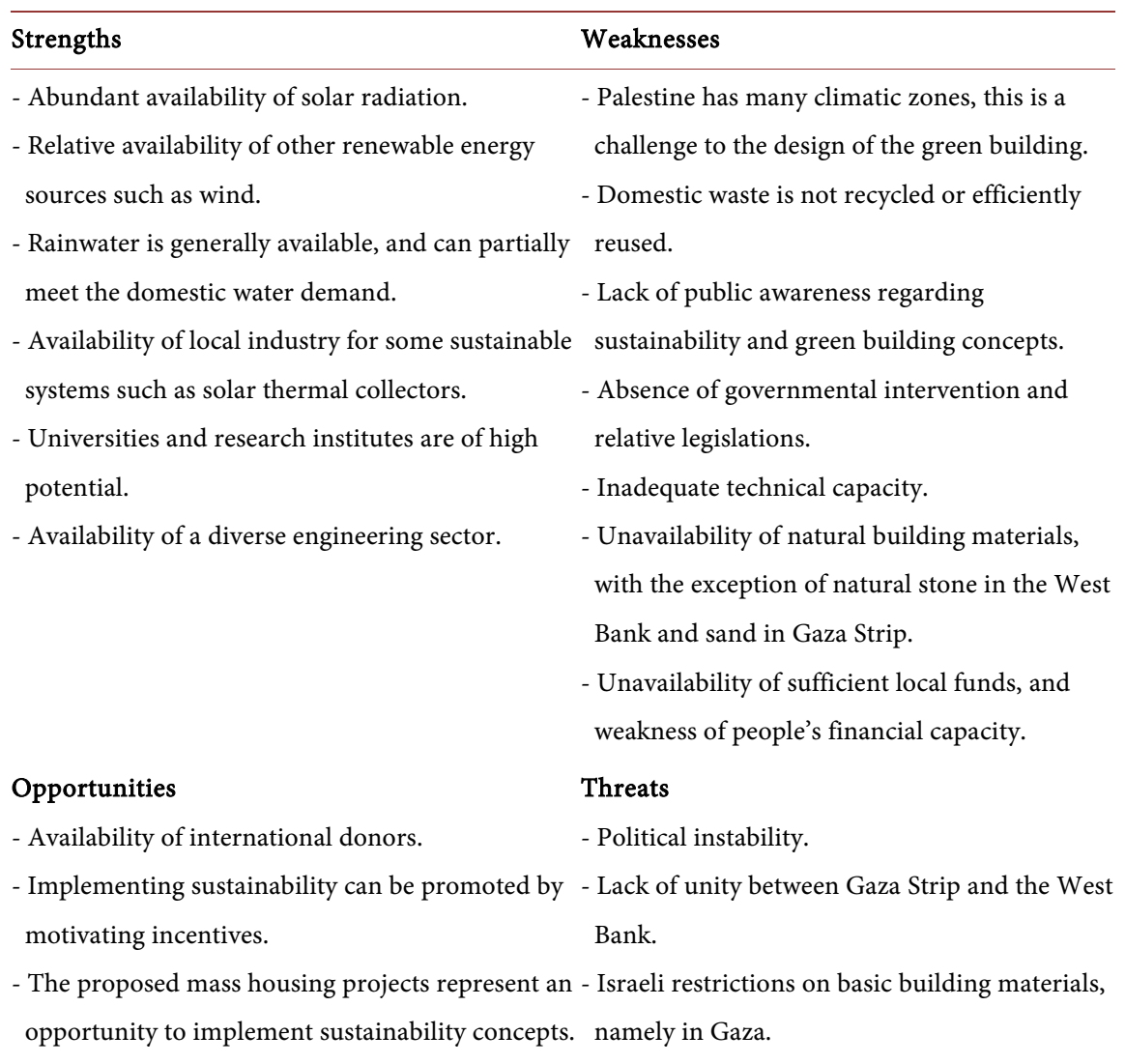




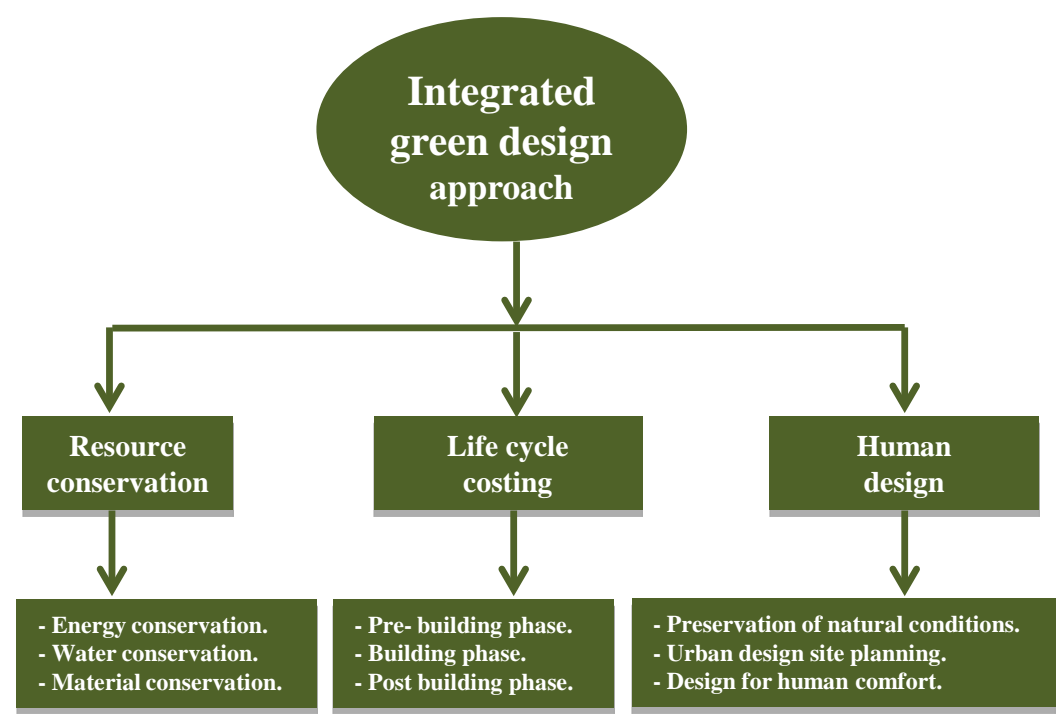

Figure 6. Steps integrated green design approach [21].

\section{Green Building Materials in Palestine}

Indeed, these challenges and opportunities could be invested to improve the building strategies currently being implemented in such a way as to rationalize the consumption of limited resources and the environment in Palestine as a developing country under difficult conditions. Here comes the important role of building materials. The most popular building material in the Palestinian construction sector is reinforced concrete. Because raw materials are not produced on site. With the exception of sand in the Gaza Strip, the main raw materials (cement, aggregates and steel bars) are imported as the use of other alternatives such as steel or wood structures is unusual or even rare. However, urban land shortages in Palestine make wooden structures impossible, especially for high-rise buildings. So, the remaining options are mainly concrete and steel. When we compare the two options, we find that steel is "greener" than concrete. This is due to several factors such as: [25]:

- Its reuse and recycling potential at relatively low energy cost. This compensates its high energy compared to concrete (steel is about twenty times higher compared to concrete).

- It requires much less transport energy compared to concrete. A typical steel building weighs about half that of a concrete one.

- It consumes less water than concrete in manufacturing process, as water is held in a closed loop and can be re-used.

Thus, steel can be used in housing production as a green option. It can be used solely or in conjunction with concrete. A wide variety of building forms and designs can be created too, where steel can be used in several components including walls, flooring, roofs, balconies, and stairs.

\section{Green Building Checklist in Palestine}

There are over forty "total quality assessment systems" which are commonly 
called green building rating systems; such as LEED in United States, BREEAM in UK, CASBEE in Japan, Minergie in Switzerland, HK Beam in Hong Kong, the Pearl Rating System for ESTIDAMA in Abu Dhabi, United Arab Emirates, and Green Pyramid Rating System (GPRS) in Egypt. The Green Buildings checklist for the State of Palestine aims to clarify the technical standards necessary to reach and evaluate sustainability requirements in buildings in the State of Palestine, with the purpose of:

a. Reducing the amount of water used in building occupations.

b. Reducing the amount of energy used in building occupations.

c. Reducing materials consumed during construction and after occupancy and encouraging their recycling.

d. Reducing the environmental impact of buildings on the surrounding environment.

e. Contribution to the creation of high efficiency, healthy, sustainable, reasonable cost and environmentally friendly buildings.

Scope of checklist application:

This checklist can be applied to most buildings that are constructed in the State of Palestine, taking into account the differences for each type. In general, this checklist can be applied to:

\ublic buildings, including:

a. Schools, universities and educational buildings.

b. Government departments, including ministries and government institutions.

c. Mosques and places of worship.

d. Administrative buildings of all kinds.

e. Cultural centers and theaters

f. Hospitals and health buildings.

\rivate buildings, including:

a. Residential buildings, including homes, villas and apartment buildings.

b. Commercial buildings, including commercial complexes and malls.

c. Meeting rooms and wedding halls.

Classification levels:

The candidate buildings are evaluated as green buildings based on a scale consisting of 200 points, through six axes, as follows:

a. Sustainability of the construction site constitutes $15 \%$ of the total points.

b. Energy efficiency is $30 \%$ of the total points.

c. Water efficiency at a rate of $25 \%$ of the total points.

d. $15 \%$ of the total points were for the quality of the internal environment.

e. $10 \%$ of the total points relate to materials and resources

f. Innovation in green building design reaps $5 \%$ of total points.

Accordingly, there are four categories based on the evaluation of green buildings in Palestine, as follows:

a. Diamond class buildings that get 160 points and more. 
b. Gold category, which is between 140 and 159 points.

c. The Silver category is a building that scores between 120 and 139 points.

d. Buildings with between 100 and 119 points are in the bronze category.

No building shall be evaluated by the Supreme Council unless it complies with the minimum mandatory requirements:

- The building must be used for at least 12 months before being evaluated on an operational and maintenance basis, with complete information on water and electricity consumption during this period.

- The building must be committed to safety measures known locally and internationally, in addition to its commitment to local building policies.

\begin{tabular}{cc}
\hline Certified & $100-119$ \\
\hline Silver & $120-139$ \\
Gold & $140-159$ \\
Diamond & $160+$ \\
\hline
\end{tabular}

\section{Leadership in Energy and Environmental Design (LEED)}

LEED stands for Leadership in Energy and Environmental Design, a green building rating system originally developed in 1998 by the U.S. Green Building Council (USGBC) to offer a well-known standard for the construction industry to evaluate the environmental sustainability levels of building designs (USGBC 2014). The announcement of the latest version of LEED was on November 20th, 2013; however, projects can still register and work with the older version of LEED until October 2016. For a project to receive LEED certification, it has to satisfy prerequisites and earn points to achieve different levels of certification. Prerequisites and credits differ for each rating system, and teams choose from among them according to their project type and stage. There are five different schemes of LEED rating system, which are as follows: 1) Building Design and Construction 2) Interior Design and Construction 3) Building Operation and Maintenance 4) Neighborhood Development 5) Homes (USGBC 2014). The LEED Assessment relies on evaluating eight main categories which are; a) Location and Transportation, b) Sustainable Sites, c) Water Efficiency, d) Energy and Atmosphere, e) Materials and Resources, f) Indoor Environmental Quality, g) Innovation, and 8h) Regional priority. Projects applying for LEED certification should consider these categories and their specific prerequisites. The project must then pursue a set of credits in order to earn points. Additionally, some of the requirements under selected categories are obligatory and required in order to receive LEED certification. The number of points the project earns determines its level of LEED certification. A project that earns 40 - 49 points from the different categories would be "Certified", whereas a project that earns 50 - 59 points is "Silver", a project with 60 - 79 points is "Gold" and a project with more than 80 - 110 points would be "Platinum" (USGBC 2014). There is a direct connection between rating systems for green buildings and the sustainable development 
of a country.

\section{Green Building Checklist in Palestine}

A clear relationship was observed between a continent's green building evaluation systems and sustainable development. Certification systems promote the development of sustainable design and construction, which lead to the mitigation of climate change and ensure environmental, economic and social sustainability. The objective of GPRS is to provide green credentials for the assessment of buildings in Palestine through raising awareness of the necessity of green buildings according to the Palestinian context and conditions. There is a direct relationship between green building assessment systems and sustainable development of a country. Certification systems promote the development of sustainable design and construction, which lead to the mitigation of climate change and ensure environmental, economic and social sustainability. Our proposed green building checklist aims to give appropriate local assessment system this regards. Our aims to increase the awareness in field of green building design and enabling to start giving certifications according to (LEED \& towards Palestinian green building standards) for green building design and development. After each aspect, the design team should cover a list of sub-aspects. For example, the design team must carefully study and select the most appropriate wall insulation, window-to-wall ratios, external shading devices and glazing specifications when it comes to the subject of the building envelope. The authors add that the local context defines the number of credits, or percentages, assigned to a particular category. It is important that the rating system chosen for a particular project covers issues related to the country in which it was built. Even for countries in the same region, the size and importance of certain categories may vary based on availability and value. Architects, engineers and designers agree that the key to reducing the cost of green buildings lies in an integrated design approach. The integrated design process takes into account time management and the union of relevant parties to investigate various alternatives prior to issuing the final draft. This approach takes a complete perspective and takes into account and ensures coverage of all designs disciplines together instead of looking at it from one angle. The project must then aim for a number of credits to earn points. Additionally, some of the Requirements under selected categories are mandatory and required to obtain LEED certification. The number of points the project earns determines the LEED level Certification. A project that deserves 40 - 49 points from the different categories would be "Certified" while a project that earns 50 59 points is "Silver", a project that earns 60 - 79 points is "Gold" and a project with more than 80 - 110 points would be "Platinum" (USGBC 2014). The purpose of the proposed Green Building: Checklist is tool to facilitate transformation towards green building in Palestine by Working with industry to help co-define what defines "green building" in the Palestine context. In addition, Improving the City's ability to facilitate, enable and approve green buildings in a 
timely fashion. Furthermore, establishing a framework to assist in standardizing City approvals processes for green components of building.

\section{Proposed Checklist for Green Building in Palestine}

Proposed Green Building Checklist, have a direct relationship between green building assessment systems and sustainable development of a country. Certification systems promote the development of sustainable design and construction, which lead to the mitigation of climate change and ensure environmental, economic and social sustainability. Our proposed green building checklist aims to give appropriate local assessment system this regards (see the under-mention tables).

\begin{tabular}{lllll}
\hline Yes & No & & \\
\hline 1 & 9 & 1. Site sustainability & 30 Points-15\% \\
\hline Y & & Pre required $\quad$ Construction activity pollution prevention &
\end{tabular}

\section{Site Selection}

1 1. Site selection on previously developed lands or grey fields available lands within urban areas.

12 . That the construction site is not agricultural land, or classified as a nature reserve, or unexploited land Previously are located within a range in river or rain floods, or less than 15 meters from Bodies of water and less than $30 \mathrm{~m}$ from the Wetlands.

13 . Availability of basic services and public transportation within $800 \mathrm{~m}$. environment and utilizing existing infrastructure during the implementation of the plan.

1 6. Provide a paved road to reach from the main road to the car park via building entrance with a width not less than $1.2 \mathrm{~m}$.

19 . Maintaining open spaces on the site such as parks and beaches or increasing the area of open spaces through site design.

1 11. Reduce dependence on potable water to irrigate plants on site and replace with reclaimed gray water.

Outdoor Thermal Comfort Strategy

2 13. Use design strategies such as proper orientation, shading, ventilation, and bulk storage (use at least two of these strategies). 2

\section{Urban Heat Island Effect}

1 16. Using green roofs is not less than $50 \%$ of the project area. 1 


\section{Continued}

\section{Light Pollution Reduction}

\section{Alternative Transportation}

2

19. Ensure that the distance between the main project entrance and the nearest public transport station is not more than 400 meters.
20. Provide a place and equipment for using bicycles at a distance of no more than 200 meters from the entrance to the project. 2

\section{Water Harvesting}

121 . Using rainwater management system during and after storms. 1

22 . A strategy to collect and treat at least $90 \%$ of the water. 2

$1 \quad$ 23. Existence of program for maintaining of the storm water management system. 1

\begin{tabular}{llll}
\hline 20 & 10 & 2. & Indoor Environment Quality \\
\hline
\end{tabular}

Y Pre required Minimum indoor air quality performance

Y Pre required Smoking control

Ventilation and Air Quality

1 1. Installing a carbon dioxide level monitor.

12 . Increasing $15 \%$ in the rate of ventilation over the rate of forced ventilation.

$2 \quad 3$. Using natural ventilation. 2

Hazardous Material

4. Ensure that the sticky materials used meet local and international standards.

1 5. Confirming that the used paints meet local and international standards.

6. Confirming that the materials used (Asbestos, Carpet \& Hard Flooring, Ceiling Systems and Formaldehyde) meet local and international standards.

\section{Car Park Air Quality Management}

7. Emphasize that the ventilation design of the car park match or exceed the specified level of air pollutant concentration

2 which meet local and international standards. In cases that the project does not contain closed garages with a closing ratio of 2 less than $75 \%$, the points are given automatically.

\section{Thermal Comfort}

1 8. Confirming on zoning thermal and control devices.

9. For industrial ventilation: one point when providing a control device for every two people and another point when providing a device (occupancy sensor).

1

10. For mixed ventilation: one point when providing windows with manual control for natural ventilation for $50 \%$ of the used areas and two points when providing natural ventilation for $75 \%$ of the used areas.

11. Emphasizing the use of thermal modeling calculations during the design process via Predicted Mean Vote (PMV) and Predicted Percentage Dissatisfied (PPD) accordance with local and international standards.

High Frequency Lighting

12. Public buildings: All lighting units used meet the local and international standards.

Residential buildings: $95 \%$ of the lighting units used meet local and international standards.

Daylight and Glare

13. Public buildings: achieve at least 250 lux for $75 \%$ of used spaces.

Residential buildings: At least 200 lux for $75 \%$ of living rooms and bedrooms.

Schools: achieve a minimum of 300 lux for $90 \%$ of the spaces used. 


\section{Continued}

\section{View}

\section{Sound Transmission}

15. Sound transmission coefficient in external walls STC $>50 \mathrm{db}$.

1 16. Sound transmission coefficient in interior walls and floors STC $>50 \mathrm{db}$.

1 17. The transmission coefficient of sound resulting from roads or collisions in the floors IIC $>56 \mathrm{db}$.

Safe \& Secure Environment

18. All pollutants conform to the specified specifications and not exceed the local and international standards.

\begin{tabular}{llll}
45 & 15 & 3. Energy Use Efficiency \\
\hline $\mathrm{Y}$ & & Pre required & 1. Planning for building energy systems. \\
$\mathrm{Y}$ & Pre required & 2. Achieve minimum energy efficiency and consumption. \\
$\mathrm{Y}$ & Pre required & 3. Planning to manage cooling systems in the building.
\end{tabular}

Achieving the best minimum use energy efficiency.

5 4. Ensure that the upper limit of the thermal conductivity of the walls is not exceeded.

5 5. Ensure that the upper limit of the thermal conductivity of the upper ceiling is not exceeded.

3 7. Ensure that the maximum windows shading factor is not exceeded.

3 8. Ensure that the minimum light transmittance of windows is not exceeded.

\section{Exploiting Renewable Energy}

$4 \quad$ 12. Using solar and wind energy to generate electricity. 4

13. Using solar heaters to heat water.

4 14. Use of ground energy or bioenergy.

Efficiency of equipment and devices used in buildings

(Air conditioning devices and systems)

1 15. Commitment to the efficiency of the devices used. 1

1 16. Commitment to using environmentally friendly materials in the manufacture of these devices. 1

1 17. Adhere to the permissible noise level. 1

1 18. Using efficient controllers to control usage. 1

0.5 19. Controllers can be linked with BMS (Building Management System). 0.5

120 . Use of variable motors with Inverter. 1

$\mathbf{0 . 5} 21$. Use of energy recovery systems 0.5

Efficiency of equipment and devices used in buildings

(Water heating devices)

122. Use of temperature control devices. 


\section{Continued}

12 23. Insulation for hot water pipes.

$\mathbf{0 . 5}$ 24. Use of covers for heated swimming pools.

$\mathbf{0 . 5} 25$. Use of energy recovery systems for ponds.

Efficiency of equipment and devices used in buildings

(Efficiency of washing machines, utensils and refrigerators.)

126 . Commitment using highly energy and water efficient washing machines.

1 27. Commitment using dishwashers with high energy and water efficiency

128 . Commitment using energy-efficient refrigerators.

\section{Smart Buildings}

$31 \quad 19 \quad 4$. Water Use Efficiency

50 Points-25\%

Y Pre required 1. Water use efficiency.

\section{Reducing Water Consumption}

2. Achieving a general reduction in potable water consumption by not less than $30 \%$ through the selection of highly efficient ${ }_{8}$ water-consuming equipment.

6

3. Exploiting additional water resources (for example: rain harvesting, greywater treatment, condensed water, etc.) to increase the general reduction of water consumption by not less than $20 \%$.

Rationalize the production and consumption of hot water

5. Using alternative energy sources such as solar energy to meet the needs of hot water consumption and distribution in the building at a rate of not less than $75 \%$ of public consumption.

6. Selection of equipment, tools, devices and materials used in the production, supply and distribution of hot water inside the

4 building with a total efficiency of not less than $90 \%$ and the optimal use of energy consumption. (Optimization of Energy 4 Resource)

7. Controlling consumption, adjusting the temperature of the hot water supplied to all points of use, and controlling the circulation of water in the distribution of hot water.

1 8. Protection and treatment systems against corrosion and calcification and provide security and safety devices to maintain the sustainability of the hot water system.

19 9. Energy or heat retrieval from air conditioning, cooling and heating equipment.

Rainwater harvesting efficiency

\section{Exploiting Gray Water}

3 12. Provide a gray water collection system. 


\section{Continued}

2 16. Existence of systems to control the quality of potable and non-potable water, and taking care of all its components against any health and environmental risks.

1

17. Existence of security and safety systems and mechanisms for using the water system in the building, identifying sources of dangers and containing dangerous events.

18. Existence of awareness and educational plans in the rationalization of water consumption and use targeting owners, users, operators, technicians and visitors to buildings.

\begin{tabular}{|c|c|c|c|c|}
\hline 12 & 8 & \multicolumn{2}{|c|}{ 5. Materials and Resources } & 20 Points- $10 \%$ \\
\hline $\mathrm{Y}$ & & Pre required & 1. Construction and Operation Waste Management Program. & \\
\hline $\mathrm{Y}$ & & Pre required & 2. Not using hazardous materials. & \\
\hline
\end{tabular}

Use non-polluting materials for the environment

13 . The thermal insulation materials used in the project are non-ozone depleting materials $(\mathrm{ODP}=0)$, and do not contribute to global warming.

1 4. Not use materials with low toxicity.

15 . Not use chlorine containing materials.

\section{Using local materials}

2 6. Local material cost equals $10 \%$ of the total material cost. 2

27 . Local material cost equals $20 \%$ of the total material cost. 2

\section{Recycled Materials}

8. $50 \%$ of all steel structures (by weight) contain $25 \%$ of materials recycled or reused and $80 \%$ of total steel reinforcement or steel (by weight) has $90 \%$ of recycled or reused materials.

19 . The project may reduce the overall amount of Portland cement used and the associated greenhouse gas emissions.

$1 \quad 10.15 \%$ of moraine used on site (by volume), in both structural and non-structural applications, are from recycled materials. 1

The use of rapidly renewable materials

2 11. Use at least $50 \%$ of the wood to be used from certified fast wood renewable, which is replanted quickly.

Materials Reuse

2

12. Reuse of previously used materials at a rate of not less than $5 \%$ of the amount of materials used in the project, or with a value of not less than $10 \%$ of the value of those materials.

\section{Materials Durability}

2

13. Using of materials with a high ability to resist natural conditions such as expansion and contraction, as well as with standing radiation The sun and the high or low humidity, in addition to its ability to resist living elements such as fungi, 2 insects and others.

\section{Building Reuse}

14. Use of usable items such as walls, floors, and various ceiling elements as well Interior doors, windows and walls. The area 2 of the internal non-structural elements must not be reduced Used for $50 \%$ of the building area.

\section{Design for Flexibility and Disassembly}

2 15. Design the building in such a way that it can easily reuse its structural and non-structural elements upon completion the use of the building, and used connection materials and elements that can be easily dismantled with minimal losses.

\section{2}

10 Points $-5 \%$

\section{Innovation in Design}

4 1. Creative design ideas.

Design and build integration

3

2. Architectural and technical solutions that are inspired by the local culture and environment and award one point for each 3 creative idea, with a maximum of 3 points. 


\section{Continued}

Using modern technologies

1

\section{Recommendations}

The research covered the green building and sustainability status in Palestine and the green building materials status in Palestine. Finally, the study suggested a checklist to assess the status of buildings in Palestine and the extent to which they react to the principles of sustainable green building development.

The field of life, including the construction and surrounding areas, is currently facing distinct challenges related to the use of building technology and the scope for alternatives to green building design. In this edition, sustainable green building techniques play an important role as they serve a set of potential and advantages to establish a sustainable approach to green building in architecture that corresponds to the local context in Palestine. To develop, in accordance with current, a better pattern for the future. In this regard, a set of guidelines to be considered by architects, local organizations and governments to plan, monitor and improve the reality of sustainable design of environmentally friendly buildings and standard green building techniques in Palestine are highlighted as follows:

- The principles and the work methodology of green building architecture have to take their place in all cities in Palestine, as the green building approach has many values and advantages.

- Refurbishment of the existing buildings to fit the sustainability green building principles is crucial, as the green building has the potential to be used efficiency in Palestine context.

- Utilize the green buildings as a passive design technique, has many environmental, cultural, and social values; it could play a good role in the concepts of sustainability green building.

- The orientation of the new green building must be carefully determined regarding the climate and the site features, to take use of sunlight, natural ventilation, shade, etc.

- The governmental institutions have to economically encourage the different sectors of society to refurbish their own building by the green building technique, and also technically by generalizing green building techniques and advanced models of sustainable green building.

- As a part of public awareness, the local society should be learned through their direct involvements in the developmental projects of sustainable green building.

- We can say, that the idea and purpose of living and working in green building is It provides comfort, healthy living and increases the productivity of green building occupants. 
- Its clearly that the sustainable green building is a global contemporary trend enhancing historical local identity and other important values.

- Maintaining and increasing the contribution of construction industry in the economy by reducing cost, saving energy, saving resources, time and reducing the on-going cost of maintenance.

- Maintaining and Increasing the contribution of construction industry in the economy by reducing cost, saving energy, saving resources and time.

- Incentives for innovation and new projects such as recycling and reuse materials and enhance cooperation between construction chains.

- Continuous training and promoting skills of work forces.

\section{Conclusions}

Green building applications in the construction are not a conceptual benefit, but a new scientific approach for professional practice in planning, tracking, planning and construction methods for our residential and architectural facilities, and for the quality of the design decisions taken by the architect and engineer to strengthen the concept of designing and evaluating construction processes and procedures. These actions, reached in the engineering and consulting office paths, have become a huge economic burden on citizens, economies and governments. This paper discussed sustainable green building in terms of key principles for sustainable building, green building sustainable design strategies and direction. Also, this research has shaded some light on the following themes to comprehend the history of green construction:

- Climate Change Interference (Global warming);

- Sustainable design principles;

- Criteria for Green Building ranking (LEED);

- Proposal of an acceptable evaluation checklist for newly planned and old facilities to comply mostly with environmentally sustainable certification.

There are some obstacles to the implementation of the proposed checklist and guidelines for green building design in Palestine. This research is aimed at Palestinian architects, designers, and engineers who wish to use measurement terms as a green building. First, you need to fulfill our recommended request. Users must get the percentage of project results immediately after filling in the details and calculating the points for each item to get a green design certificate with total points. We strongly recommend encouraging the use of the proposed green building checklist to obtain a real local measure of compliance with LEED standards (see Chapter 7).

\section{Conflicts of Interest}

The authors declare no conflicts of interest regarding the publication of this paper.

\section{References}

[1] Iyengar, K. (2015) Sustainable Architectural Design: An Overview. Routledge, New 
York. https://doi.org/10.4324/9781315758473

[2] UNEP (2011) Towards a Green Economy: Pathways to Sustainable Development and Poverty Eradication. United Nations Environment Program (UNEP).

https://sustainabledevelopment.un.org/index.php?page $=$ view\&type $=400 \& n r=126 \&$ $\underline{\text { menu }=35}$

[3] Kats, G., Alevantis, L., Berman, A., Mills, E. and Perlman, J. (2003) The Costs and Financial Benefits of Green Buildings. A Report to California's Sustainable Building Task Force, U.S. Green Building Council.

https://noharm-uscanada.org/documents/costs-and-financial-benefits-green-buildi ngs-report-california\%E2\%80\%99s-sustainable-building-task

[4] Yudelson, J. (2007) Green Building A to Z: Understanding the Language of Green Building. New Society Publishers, Gabriola Island.

https://scholar.google.com/scholar_lookup?title=The\%20Green\%20Building\%20Re volution \&author $=$ I.\%20Yudelson\&publication year $=2008$

[5] Kubba, S. (2012) Handbook of Green Building Design and Construction. Elsevier, Amsterdam. https://doi.org/10.1016/B978-0-12-385128-4.00003-2

https://www.sciencedirect.com/book/9780123851284/handbook-of-green-buildingdesign-and-construction\#book-info

[6] Laustsen, J. (2008) Energy Efficiency Requirements in Building Codes, Energy Efficiency Policies for New Buildings. International Energy Agency (IEA), Paris. https://www.iea.org/publications/freepublications/publication/Building_Codes.pdf

[7] Cole, R.J. (2013) Rating Systems for Sustainability. In: Loftness, V. and Haase, D., Eds., Sustainable Built Environments, Springer, New York, 464-477. https://link.springer.com/referencework/10.1007\%2F978-1-4614-5828-9

[8] Burnett, J., Chau, C. and Lee, W. (2005) Green Buildings: How Green the Label? HKIE Transactions, 12, 1-8. https://doi.org/10.1080/1023697X.2005.10668014 https://www.tandfonline.com/doi/abs/10.1080/1023697X.2005.10668014

[9] Alatawneh, B., Germana, M. and Carrao, R. (2015) Near Zero Energy House in Palestine: Identification of the Future Challenges. 5th International Energy Conference, Ramallah, 27-28 January 2015, 47-50.

[10] Hodiri, H. (2018) Assessing the Actual Performance of Green Buildings in Palestine: A Case Study. Master Thesis, An-Najah National University, Nablus. https://repository.najah.edu/handle/20.500.11888/14171

[11] Hussein, H. (2010) Courtyard Concept: A Sustainable Strategy for the Future Housing Buildings in Palestine. Conference. Sustainable Architecture \& Urban Development “SAUD 2010", Amman, July 2010, 271-285. https://www.researchgate.net/publication/258237440

[12] Salameh, W. (2012) Towards Sustainable Construction Systems of External Walls of Buildings in the West Bank of Palestine. Master Thesis, An-Najah National University, Nablus. https://repository.najah.edu/handle/20.500.11888/7418

[13] Abdel Hadi, M. (2013) Possibility of Developing Environmentally Friendly Residential Buildings in Palestinian Cities-A Study Case from the Cities of Jenin and Ramallah. Master Thesis, Arabic Language Thesis, An-Najah National University, Nablus. https://repository.najah.edu/handle/20.500.11888/7449

[14] Hussian, H., Barlet, A., Baba, M. and Semidor, C. (2016) Evaluation for Environmental Comfort Performance in the Palestinian Schools. 32nd International Conference on Passive and Low Energy Architecture-Cities, Buildings, People: Towards Regenerative Environments, Los Angeles, July 2016, 1254-1261.

https://www.researchgate.net/publication/308762434 
[15] Saadeh, B. (2014) An Evaluation Study of the Green Governmental Schools in the West Bank. Master Thesis, An-Najah National University, Nablus.

[16] Juaidi, A., Montoya, F.G., Ibrik Imad, H. and Manzano-Agugliaro, F. (2016) An Overview of Renewable Energy Potential in Palestine. Renewable and Sustainable Energy Reviews, 65, 943-960. https://doi.org/10.1016/j.rser.2016.07.052

https://www.sciencedirect.com/science/article/pii/S136403211630380X?via\%3Dihub

[17] Kitaneh, R., Alsamamra, H. and Aljunaidi, A. (2012) Modelling of Wind Energy in Some Areas of Palestine. Energy Conversion and Management, 62, 64-69. https://doi.org/10.1016/j.enconman.2012.04.008

[18] Nazer, D.W., Maarten, A.S., Van der Zaag, P., Mimi, Z. and Huub, J.G. (2008) Water Footprint of the Palestinians in the West Bank. Journal of the American Water Resources Association, 44, 449-458.

https://doi.org/10.1111/j.1752-1688.2008.00174.x

[19] Palestinian Central Bureau of Statistics (PCBS) (2017) Geography and Climate Conditions. Ramallah.

[20] Said, N. and Alsamamra, H. (2019) An Overview of Green Buildings Potential in Palestine. International Journal of Sustainable and Green Energy, 8, 20-33.

https://doi.org/10.11648/j.ijrse.20190802.11

[21] Albaba, I. (2016) The Herpetofauna of Palestine: A Preliminary Checklist. Journal of Entomology and Zoology Studies, 4, 123-128.

[22] Haddad, H. (2010) A Framework of Sustainable Design for the Region of Palestine. Master Thesis, College of Arts \& Architecture, The Pennsylvania State University, State College.

[23] Whole Building Design Guide WBDG (2015) Sustainable. National Institute of Building Science. https://www.wbdg.org/design/sustainable.php

[24] AAS Architecture (2014).

http://aasarchitecture.com/2014/01/completed-the-king-fahad-national-library-bygerber-architekten.html

[25] Edwards, B. and Hyett, P. (2002) Rough Guide to Sustainability. RIBA, London. 